\title{
Comparison between Induction of Ovulation with Clomiphene Citrate with or without Withdrawal Bleeding in Patients with Polycystic Ovary Syndrome
}

\author{
S.A.El-bery, T.M.Asar,A.M.Bayomy and E.G.Abdelfatah \\ Obstetrics , Gynecology Dept., Faculty of Medicine, Benha Univ., Benha, Egypt \\ E-Mail: elmasry_101@yahoo.com
}

\begin{abstract}
Polycystic ovary condition (PCOS) is a typical heritable and heterogeneous issue described by ovulatory brokenness with hyperandrogenic status, notwithstanding the polycystic morphology of the ovaries. Treatment of anovulation begins with weight decrease in fat ladies, through to careful control of the ovaries. A few medicines been utilized for acceptance of ovulation. This investigation expected to assess the impact of clomiphene citrate in enlistment of ovulation in patients with polycystic ovarian syndrome(PCOs) without prompting withdrawal seeping in examination with the conventional convention of clomiphene citrate. Techniques: complete of 60 barren ladies matured $20-40$ years of age with the conclusion of PCOS , who introduced to Benha University Hospital at the barrenness outpatient facility, were enrolled for the investigation , all patients were arbitrarily isolated into two gathering :Group 1 (study gathering ): Group II (Control gathering ): Transvaginal ultrasound folliculometry was done $5-7$ days after finish of $\mathrm{CC}$ treatment . Results: This examination had indicated that the all out number of follicles, mean follicular width and endometrial thickness after incitement was altogether more when beginning CC in (luteal stage) than (follicular phase).Conclusion:Early organization of CC in late luteal stage (before withdrawal shedding) in patients with PCOS may prompt more follicular development, ovulatory patients and endometrial thickness which may ponder higher pregnancy rate than organization of $\mathrm{CC}$ in early follicular stage (from second day to fifth day of cycle).
\end{abstract}

Keywords: Induction of ovulation,Clomiphene citrate,Withdrawal bleeding, PCO.

\section{Introduction}

Polycystic ovary condition (PCOS) is a typical heritable and heterogeneous issue portrayed by ovulatory brokenness with hyperandrogenic status, notwithstanding the polycystic morphology of the ovaries, Prevalence shifts from $6 \%$ to $21 \%$ of ladies [1].

A few investigations proposed that this variety in the pervasiveness of PCOS is credited chiefly to the symptomatic measures utilized [2].

Roughly $30 \%$ of ladies with PCOS have ordinary menstruation, butoligomenorrhea and amenorrhea are regular aggravations [3].

It is a typical reason for auxiliary amenorrhea: $30-40 \%$ of ladies with amenorrhea were found to have PCOS.It is additionally the most well-known reason for constant hyperandrogenic anovulation [4].

The executives system in PCOS is controlled essentially of introduction, that is, feminine problems, androgenabundance side effects or fruitlessness [5].

Treatment of anovulation begins with weight decrease in hefty ladies, through to careful control of the ovaries. A few medicines have been utilized for enlistment of ovulation. Clomiphene citrate (CC), an incompletely particular estrogen receptor modulator, is right now the first-line pharmacological treatment for ovulation enlistment in PCOS [6].

It irritates the negative criticism of estrogen at the degree of the nerve center, instigating a difference in the beat recurrence of gonadotropin-releasing hormone (GnRH), which prompts expanded creation of follicle-stimulating hormone (FSH) from the pituitary organ [7].

CC treatment is regularly observed with ultrasonography for follow up of number and size of preovulatory follicles and endometrial thickness [8].
The revealed ovulation rate with $\mathrm{CC}$ goes from $70 \%$ to $85 \%$ per cycle.The legitimate portion and timing of treatment have been the subject of a few examinations since the presentation of CC. Traditionally, the beginning portion of $\mathrm{CC}$ is $50 \mathrm{mg} /$ day for 5 days beginning on days 2-5 after an unconstrained or progestin-induced withdrawal drain. The portion can be expanded to a greatest portion of $150 \mathrm{mg} /$ day for six cycles [6].

Prior beginning of CC treatment has been proposed: a few agents revealed higher pregnancy rates with treatment commencement on day 1 contrasted and day 5 , even with a $50-\mathrm{mg} /$ day portion [9].

Another examination supported that early CC brought about more follicular development and endometrial thickness in patients with PCOS [10].

A later randomized controlled preliminary examined treatment inception before withdrawal draining initiated with nor ethisterone acetate(Steronate $(B)$, and noticed a higher number of follicles, thicker endometrium, and higher serum E2 with early CC treatment [11].This examination intended to assess the impact of clomiphene citrate in acceptance of ovulation in patients with polycystic ovarian syndrome(PCOs) without inciting withdrawal seeping in correlation with the customary convention of clomiphene citrate.

\section{Patients and methods}

The present study was designed as a prospective controlled study, was conducted at the infertility out-patient clinic of Benha University Hospital, during the period from August 2019 to September 2020. It included 60 infertile women who were diagnosed as having PCOS. 
2.1Inclusion criteria of patients in the study

A. Women aged 20-40 years old who had amenorrhea for at least 3 months.

B. Patients with diagnosis of PCOS based on the 2003 ESHRE/ASRM (Rotterdam) criteria: to include two of the following, in addition to exclusion of related disorders:

1. Oligo / anovulation.

2. Hyperandrogenism and/or Hyperandrogenemia.

3. Polycystic ovaries (presence of 12 or more follicles in at leastone ovary, measuring $2-9 \mathrm{~mm}$ diameter, or increased ovarianvolume greater than $10 \mathrm{~cm}^{3}$ ).

\subsection{Exclusion criteria of patients in the study}

A. Age is less than 20 or more than 40 .

B. Major pelvic pathology.

C. Ovarian masses.

D. Infertility due to causes other than ovarian factors e.g. 1. Bilateral tubal block

2. Congenital anomaly of the uterus

3. Male factor of infertility

E. Liver disease.

F. Other endocrinopathies e.g. hyperprolactinemia, Late Congenital Adrenal Hyperplasia (LCAH), hypothyroidism, hyperthyroidism and Cushing's disease.

G. Women with amenorrhea and no withdrawal endometrialshedding after progesterone challenge test [Norethisterone acetate $5 \mathrm{mg}$ two times per day for 5 days].

H. Patients who got pregnant at the start or middle (wash out period) of the study as they couldn't enter crossover stage.

\section{Research question}

Patients: Women with diagnosis of PCOS based on the 2003 ESHRE/ASRM (Rotterdam) criteria.

Intervention: Early Clomiphene Citrate induction protocol (Late luteal phase) before withdrawal endometrial shedding.

Comparison: Late Clomiphene Citrate induction protocol (Early follicular phase) after withdrawal endometrial shedding.

Outcome: The primary outcome measures are the total number of follicles $(\geq 14 \mathrm{~mm}+\geq 18 \mathrm{~mm})$, number of follicles $\geq 14 \mathrm{~mm}$ in diameter, number of follicles $\geq 18 \mathrm{~mm}$ in diameter, endometrial thickness. The secondary outcome measureis number of ovulating patients.

Study analysis: The main analysis between early induction protocol (Group I) vs. late induction protocol (Group II).

\section{Method}

All subjects after consenting were subjected to the following:

\section{Full history taking including}

Personal history, complaint, history of present illness, menstrual history, gynecological history, family history, past history and sexual history.

\section{Full clinical examination including}

- General examination: was performed including body weight andheight and clinical assessment of BMI (body weight in kilogram divided by height in meters squared ).

- Abdominal examination: was done to detect any superficial or deep swelling, tenderness or rigidity.

- Pelvic and local examination.

The following parameters were measured before treatment

Basal serum follicle stimulating hormone (FSH) in (mIU/L), basal serum luteinizing hormone (LH) in (mIU/L), basal serum prolactin in $(\mathrm{ng} / \mathrm{ml})$, free and total testosterone in $(\mathrm{ng} / \mathrm{ml})$ and thyroid stimulating hormone $(\mathrm{TSH})$ in (mIU/L) were determined on days 2 or days 3 of the previous cycle.

\section{Withdrawal bleeding}

- Was achieved using 10-mg tablets of norethisterone acetatedaily for 5 days to induce withdrawal bleeding before stimulation.

Then all Patients were randomly divided into two groups:

- Group I(study group): included 30 patients to whom $50 \mathrm{mg}$ ofclomiphene citrate (CC) - Clomid®, SanofiAventis, termi, Egypt); was administered twice daily for five days without inducing withdrawal bleeding .

- Group II(control group): included 30 patients to whom $50 \mathrm{mg}$ of clomiphene citrate (CC) was administered twice daily for five days starting on day three of the cycle induced bynorethisterone acetate 10 $-\mathrm{mg}$ tablets for 5 days

\section{Transvaginal ultrasound folliculometry}

was done on day 5th and day 7th after end of CC treatment and the patients were followed up by transvaginal ultrasound till a leading follicle of $18 \mathrm{~mm}$ diameter was reached, then number of mature follicles,endometrial thickness in millimeters and cycle day at reaching mature follicle were determined.

\section{Techniques}

\section{Ultrasound folliculometry}

In the current investigation, ultrasound folliculometry was done in Benha University Hospital at the fruitlessness outpatient facility utilizing vaginal test of voluson genius V 730.

Procedure of transvaginal Ultrasound:

The reason for the methodology and its favorable circumstances were disclosed to every patient, and assent was taken, to be agreeable and not restless.

Every patient was encouraged to exhaust the bladder before assessment.

The patient was approached to lie in prostrate situation, on a standard gynecological assessment table with raised thights to permit free development of the vaginal test in the even plane. The test tip was covered with sterile gel and brought into a latex condom, which was additionally greased up with gel before inclusion. The test was brought into the vagina and controlled in coronal and sagitalplanes, 
anteriorly and posteriorly comparative with the structures to be inspected.

A Scanning routine was followed: toward the starting the cervix was checked trailed by the uterus and afterward the adenexa and cul-de sac.The ovary is a lot simpler to picture when it contains follicles, Then the output was dissected for observing follicular turn of events.

\section{The method of transvaginal U/S \\ 1- Ovarian examination}

Comment on ovarian morphology, number and size of follicles. The dominant follicle was measured in two planes:

Transverse and anteroposterior in $\mathrm{mm}$ from inner to inner, then the mean follicular diameter was then calculated. U/S was done later to detect ovulation on the basis of alteration in the shape or size of the follicle and by the presence of fluid in the cul-de-sac [12].

\section{2- Endometrial thickness}

The endometrium was measured by longitudinal scans including the whole endometrium at the point of its maximum thickness; both endometrial outer limits were included in the measurement [12].

\section{Statistical analysis}

The collected data were tabulated and analyzed using SPSS version 20 software (SpssInc, Chicago, ILL Company). Categorical data were presented as number and percentages, Chi Square ( $\chi 2), Z$ of proportions (ZProp.) and Fisher's exact tests were used to analyze them. Quantitative data were tested for normality using ShapiroWilks test assuming normality at $\mathrm{P}>0.05$. Normally distributed variables were expressed as mean \pm standard deviation and analyzed by student " $t$ " for 2 independent groups and Paired " $t$ " for matched variables, while nonparametric data were presented as median and interquartile range (IQR), and analyzed byMann Whitney $U$ test (ZMWU) and Wilcoxon test respectively. Non parametric correlations were assessed by Spearman's correlation coefficient (rho). P $\leq 0.05$ was considered significant[13].

\section{Results}

- This table shows that there was no statistically significant difference between the studied groups regarding the mean values of age, weight, height, or BMI ( $>0.05$ for all)Table (1).
- This table illustrates that there was no statistically significant difference between the studied groups regarding the median values of FSH, LH, PRL, TSH, or Total testosterone (all $\mathrm{p}$ values are $>0.05$ ). On the other hand, the median value of Free testosterone was significantly $(\mathrm{p}<0.05)$ higher among study group than control group (14.5 and 8.6 respectively)Table (2).

- This table demonstrates that the mean values of endometrial thickness at day $5^{\text {th }}$ and day $7^{\text {th }}$ after end of CC treatment,were significantly $(\mathrm{p}<0.05)$ higher among the study group ( 9.45 and 12.1 respectively) than the control group (8.26 and 9.89 respectively), $p$ value $<0.05$. Moreover, the mean value of increase in the endometrial thickness from day $5^{\text {th }}$ to day $7^{\text {th }}$ after end of CC treatment, was significantly higher among the study group $(2.65 \mathrm{~mm})$ than the control group (1.67 mm)Table (3).

- This table demonstrates that the median values of follicular diameter at day $5^{\text {th }}$ and day $7^{\text {th }}$ after end of CC treatment, were significantly $(\mathrm{p}<0.05)$ higher among the study group (13.9 and 18.1 respectively) than the control group (10.0 and 14.5 respectively), $p$ value $<0.05$. Moreover, the median value of increase in the follicle diameter from day day $5^{\text {th }}$ to day $7^{\text {th }}$ after end of CC treatment was significantly higher among the study group $(4.3 \mathrm{~mm})$ than the control group $(3.6$ mm) Table (4).

- This table shows that there was no statistically significant difference between the studied groups regarding the outcome of pregnancy ( $p>0.05)$ Table (5).

- This table illustrates that there were no statistically significant correlations between endometrial thickness at day $7^{\text {th }}$ after end of CC treatment and the studied variables except for the Total testosterone, where there was a significant positive correlation between them. $(\mathrm{p}<0.05)$ Table (6).

- This table shows that there was no statistically significant difference between pregnant and nonpregnant women regarding the the endometrial thickness at $5^{\text {th }}$ or day $7^{\text {th }}$ after end of CC treatment $(\mathrm{p}>0.05)$ Table (7).

- This table illustrates that there were no statistically significant correlations between follicle diameter at day $7^{\text {th }}$ after end of CC treatment and the studied variables except for the Free testosterone, where there was a significant positive correlation between them. $(\mathrm{p}<0.05)$ Table $(8)$.

Table (1) Comparing the studied groups regarding basic characters.

\begin{tabular}{lcccccccc}
\hline Variable & \multicolumn{3}{c}{$\begin{array}{c}\text { Study group } \\
(\mathbf{N}=\mathbf{3 0})\end{array}$} & \multicolumn{3}{c}{$\begin{array}{c}\text { Control group } \\
(\mathbf{N}=\mathbf{3 0})\end{array}$} & St. 't' & P \\
\hline & Mean & \pm SD & Range & Mean & \pm SD & Range & & \\
\hline Table (1) Continue & & & & & & & & \\
\hline Age (ys) & 28.7 & 3.20 & $22-34$ & 28.0 & 2.94 & $21-33$ & 0.84 & $0.40(\mathrm{NS})$ \\
Weight $(\mathbf{k g})$ & 76.3 & 10.44 & $60-90$ & 78.8 & 9.94 & $60-91$ & 0.94 & $0.35(\mathrm{NS})$ \\
Height $(\mathbf{c m})$ & 163.1 & 5.24 & $157-173$ & 161.0 & 4.81 & $155-175$ & 1.61 & $0.11(\mathrm{NS})$ \\
BMI $\left(\mathbf{k g} / \mathbf{m}^{\mathbf{2}}\right)$ & 28.8 & 3.21 & $22.3-35.2$ & 30.4 & 3.22 & $25-34.9$ & 1.96 & $0.055(\mathrm{NS})$ \\
\hline
\end{tabular}

Table (2)Comparing the studied groups regarding investigations. 


\begin{tabular}{|c|c|c|c|c|c|c|c|c|}
\hline \multirow[t]{2}{*}{ Variable } & \multicolumn{3}{|c|}{$\begin{array}{c}\text { Study group } \\
(\mathbf{N}=\mathbf{3 0})\end{array}$} & \multicolumn{3}{|c|}{$\begin{array}{c}\text { Control group } \\
(\mathrm{N}=\mathbf{3 0})\end{array}$} & \multirow[t]{2}{*}{$\mathrm{Z}_{\mathrm{MWU}}$ test } & \multirow[t]{2}{*}{$\mathbf{P}$} \\
\hline & Median & IQR & Range & Median & IQR & Range & & \\
\hline$\overline{\text { FSH }}$ & 7.1 & $6.4-9.1$ & $5.7-9.4$ & 7.2 & $6.1-7.4$ & $5.4-8.3$ & 1.45 & 0.14 (NS) \\
\hline LH & 15.2 & $11.3-16.4$ & $8.3-18.2$ & 15.2 & $13.7-16.2$ & $9.2-18.3$ & 0.44 & 0.65 (NS) \\
\hline PRL & 16.9 & $15-18.1$ & $13.7-22.5$ & 17.1 & $16.2-18.1$ & $13.8-22.0$ & 1.48 & 0.14 (NS) \\
\hline TSH & 2.1 & $1.83-2.3$ & $1.7-3.1$ & 2.05 & $1.86-2.3$ & $1.3-2.8$ & 0.68 & 0.49 (NS) \\
\hline Free testosterone & 14.5 & $6.3-21.2$ & $0.62-31.1$ & 8.6 & $4.0-15.6$ & $2.1-22.5$ & 2.16 & $0.031(\mathrm{~S})$ \\
\hline Total testosterone & 0.37 & $0.29-0.4$ & $0.07-2.3$ & 0.44 & $0.30-0.90$ & $0.06-1.8$ & 1.78 & 0.074 (NS) \\
\hline
\end{tabular}

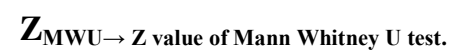

Table (3)Comparing the studied groups regarding the endometrialthickness at day $5^{\text {th }}$ and day $7^{\text {th }}$ after end of $\mathrm{CC}$ treatment.

\begin{tabular}{|c|c|c|c|c|c|c|c|c|}
\hline \multirow[t]{2}{*}{ Endometrial thickness (mm) } & \multicolumn{3}{|c|}{$\begin{array}{l}\text { Study group } \\
(\mathbf{N}=\mathbf{3 0})\end{array}$} & \multicolumn{3}{|c|}{$\begin{array}{c}\text { Control group } \\
(\mathbf{N}=\mathbf{3 0})\end{array}$} & \multirow[t]{2}{*}{ St."t" } & \multirow[t]{2}{*}{$\mathbf{P}$} \\
\hline & Mean & \pm SD & Range & Mean & \pm SD & Range & & \\
\hline $\begin{array}{l}\text { At day 5th after end of } \mathrm{CC} \\
\text { treatment }\end{array}$ & 9.45 & 1.97 & $6-12.5$ & 8.23 & 1.22 & $6.5-10.9$ & 2.88 & $\begin{array}{l}0.006 \\
(\mathrm{~S})\end{array}$ \\
\hline $\begin{array}{l}\text { At day } 7 \text { th after end of } \mathrm{CC} \\
\text { treatment }\end{array}$ & 12.10 & 1.90 & $8.5-14.8$ & 9.89 & 1.45 & $8.0-13.2$ & 3.36 & $<0.001$ (HS) \\
\hline $\begin{array}{l}\text { Paired "t" } \\
\text { P }\end{array}$ & & $\begin{array}{r}10.8 \\
.001(1\end{array}$ & & & $\begin{array}{r}5.88 \\
0.001(\end{array}$ & & & \\
\hline Increase in the ET (mm) & 2.65 & 1.2 & $1.1-7.7$ & 1.67 & 0.84 & $0.4-4.3$ & 3.45 & $=0.001(\mathrm{HS})$ \\
\hline
\end{tabular}

Table (4)Comparing the studied groups regarding follicle diameter at day $5^{\text {th }}$ and day $7^{\text {th }}$ after end of CC treatment.

\begin{tabular}{|c|c|c|c|c|c|c|c|c|}
\hline \multirow[t]{2}{*}{ Follicle diameter (mm) } & \multicolumn{3}{|c|}{$\begin{array}{l}\text { Study group } \\
(\mathbf{N}=30)\end{array}$} & \multicolumn{3}{|c|}{$\begin{array}{c}\text { Control group } \\
(\mathbf{N}=\mathbf{3 0})\end{array}$} & \multirow[t]{2}{*}{$\begin{array}{c}\mathrm{Z}_{\mathrm{MWU}} \\
\text { test }\end{array}$} & \multirow[t]{2}{*}{$\mathbf{P}$} \\
\hline & Median & IQR & Range & Median & IQR & Range & & \\
\hline $\begin{array}{l}\text { At day 5th after end of } \mathrm{CC} \\
\text { treatment }\end{array}$ & 13.9 & $12-14.1$ & $8.2-17.4$ & 10.0 & $9-12$ & $8.2-17.0$ & 3.09 & $\begin{array}{l}0.002 \\
(\mathrm{~S})\end{array}$ \\
\hline $\begin{array}{l}\text { At day } 7 \text { th after end of } \mathrm{CC} \\
\text { treatment }\end{array}$ & 18.1 & $15.9-18.7$ & $9.2-21.0$ & 14.5 & $12-18.3$ & $9.0-19.7$ & 3.29 & $=0.001(\mathrm{HS})$ \\
\hline Wilcoxon test & & 4.78 & & & 4.67 & & & \\
\hline $\mathbf{P}$ & & $<0.001(\mathrm{HS})$ & & & $<0.001$ ( & & & \\
\hline Increase in the FD (mm) & 4.3 & $3.7-5.2$ & $0.9-7.3$ & 3.6 & $2.2-4.4$ & $0.8-6.6$ & 2.19 & $0.028(\mathrm{~S})$ \\
\hline
\end{tabular}

\section{$\mathbf{Z}_{\mathbf{M W U} \rightarrow \mathbf{Z} \text { value of Mann Whitney } \mathrm{U} \text { test }}$}

Table (5)Pregnancy outcome among the studied groups .

\begin{tabular}{|c|c|c|c|c|c|c|}
\hline & & & \multicolumn{2}{|c|}{ Group } & \multirow[t]{2}{*}{ Total } & \multirow[t]{2}{*}{$\mathbf{P}$} \\
\hline & & & $\begin{array}{l}\text { Study } \\
\text { group }\end{array}$ & Control group & & \\
\hline \multirow[t]{4}{*}{ Outcome } & Pregnancy & Count & 6 & 2 & 8 & \\
\hline & & $\%$ within Group & $20.0 \%$ & $6.7 \%$ & $13.3 \%$ & $0.25(\mathrm{NS})$ \\
\hline & Non Pregnancy & Count & 24 & 28 & 52 & \\
\hline & & $\%$ within Group & $80.0 \%$ & $93.3 \%$ & $86.7 \%$ & \\
\hline \multirow[t]{2}{*}{ Total } & & Count & 30 & 30 & 60 & \\
\hline & & $\%$ within Group & $100.0 \%$ & $100.0 \%$ & $100.0 \%$ & \\
\hline
\end{tabular}

Fisher's exact test was used (FET).

Table (6)Pregnancy outcome according to endometrial thickness.

\begin{tabular}{|c|c|c|c|c|c|c|c|c|}
\hline \multirow{2}{*}{$\begin{array}{l}\text { Endometrial thickness } \\
\text { (mm) }\end{array}$} & \multicolumn{3}{|c|}{ Pregnancy $(n=8)$} & \multicolumn{3}{|c|}{ No pregnancy $(n=52)$} & \multirow[t]{2}{*}{ St. "t'" } & \multirow[t]{2}{*}{$\mathbf{P}$} \\
\hline & Mean & \pm SD & Range & Mean & \pm SD & Range & & \\
\hline $\begin{array}{l}\text { At day 5th after end of } \\
\text { CC treatment }\end{array}$ & 9.66 & 2.27 & $6.1-12.5$ & 8.71 & 1.63 & $6.0-12.5$ & 1.43 & $\begin{array}{l}0.15 \\
(\mathrm{NS})\end{array}$ \\
\hline $\begin{array}{l}\text { At day } 7 \text { th after end of } \\
\text { CC treatment }\end{array}$ & 11.37 & 2.37 & $8.0-14.8$ & 10.94 & 1.97 & $8.0-14.7$ & 0.56 & $\begin{array}{l}0.57 \\
(\mathrm{NS}) \\
\end{array}$ \\
\hline
\end{tabular}


Table (7)Correlation between endometrial thickness at day $7^{\text {th }}$ after end of CC treatment and the studied variables among study group.

\begin{tabular}{lcc}
\hline With & \multicolumn{2}{c}{ Endometrial thickness } \\
\cline { 2 - 3 } & \multicolumn{2}{c}{ Study group $(\mathbf{N}=\mathbf{3 0})$} \\
\cline { 2 - 3 } Age & rho & P \\
Weight & -0.257 & 0.17 \\
Height & -0.276 & 0.14 \\
BMI & 0.221 & 0.24 \\
Parity & -0.166 & 0.38 \\
Duration of infertility & 0.262 & 0.16 \\
FSH & -0.08 & 0.67 \\
LH & 0.288 & 0.12 \\
PRL & -0.261 & 0.16 \\
TSH & -0.244 & 0.19 \\
Free testosterone & -0.298 & 0.11 \\
Total testosterone & -0.006 & 0.97 \\
\hline
\end{tabular}

Table (8)Correlation between follicle diameter at day $7^{\text {th }}$ after end of CC treatment and the studied variables among study group.

\begin{tabular}{lcc}
\hline With & \multicolumn{2}{c}{ Follicle diameter } \\
\cline { 2 - 3 } & \multicolumn{2}{c}{$\begin{array}{c}\text { Study group } \\
\text { (N=30) }\end{array}$} \\
\cline { 2 - 3 } & rho & P \\
\hline Age & 0.186 & 0.32 \\
Weight & -0.161 & 0.39 \\
Height & 0.174 & 0.35 \\
BMI & -0.266 & 0.155 \\
Parity & 0.163 & 00.39 \\
Duration of infertility & -0.091 & 0.63 \\
FSH & 0.115 & 0.54 \\
LH & 0.182 & 0.33 \\
PRL & 0.144 & 0.44 \\
TSH & 0.106 & 0.57 \\
Free testosterone & 0.508 & 0.004 (S) \\
Total testosterone & 0.059 & 0.75 \\
\hline
\end{tabular}

\section{Discussion}

The outcomes indicated that there were no huge contrasts between ladies in the two gatherings $(\mathrm{P}>0.05)$ as respects segment information specifically; the age, the BMI , the equality and the term of barrenness .

Additionally, there were no critical contrasts between ladies in the two gatherings $(\mathrm{P}>0.05)$ as respects basal serum hormonal profile namly ; serum FSH and LH , serumL H : FSH proportion, serum prolactin .

In the current investigation, there were a factual critical contrasts between Luteal acceptance convention and Follicular enlistment convention as respects ovulating patients $(60.0 \%$ versus $26.70 \%)$ individually, too absolute number of follicles, number of follicles $\geq 14 \mathrm{~mm}$ and number of follicles $\geq 18 \mathrm{~mm}(\mathrm{P}<0.001)$.

The general discoveries of the current investigation indicated that early organization of $\mathrm{CC}$ in patients with PCOS may prompt more follicular development and endometrial thickness which may consider higher ovulatory and pregnancy rates.
This is like the aftereffects of the finding of Badawy et al., [10] who detailed an ovulation pace of $59.1 \%$ in the early CC gathering (luteal stage CC) contrasted with an ovulation pace of $51.9 \%$ in the late $\mathrm{CC}$ gathering (follicular stage CC). Additionally, announced that the all out number of follicles, number of follicles $\geq 14 \mathrm{~mm}$ and number of follicles $\geq 18 \mathrm{~mm}$ during incitement were altogether more when CC was begun early (luteal stage), likely because of bigger enrollment of follicles.

As Initiation of development of early stage follicles, alluded to as "essential enrollment", happens consistently and in an irregular manner and follicle improvement from the early stage to the preovulatory stage for the most part takes a while, the extraordinary lion's share of early stage follicles that enter this advancement stage go through atresia prior to coming to the antral follicle stage through a cycle of apoptosis. How much beginning phases of follicle advancements are affected by FSH stays muddled [14].

It very well may be recommended that promising beginning of $\mathrm{CC}$ in the later piece of the luteal period of the former cycle will be liable for more follicular enrollment [15]. 
These outcomes are with incomplete concurrence with certain investigations which announced that more quick follicular development and higher pregnancy rate when $\mathrm{CC}$ was begun on day 1 as opposed to on day 5 of menses [9].

In any case, the consequences of the current investigation can't help contradicting Kosar et al., [11] who announced that there were no critical distinction in ovarian reaction and pregnancy rates between bunches beginning $\mathrm{CC}$ on the second, third, fourth, or fifth day of the cycle.

Chen et al., [16] found that the quantity of follicles delivered was uniquely expanded, oocytes were recovered and treated in cycles in which CC was started on day 5 .

Too, Hembram et al., [17] found that, during treatment, gonadotropin levels expanded for 10 to 14 days after commencement of $\mathrm{CC}$ in the two gatherings. The quantity of huge follicles (14 $\mathrm{mm}$ or more) and greatest size of follicles were notably higher in day 5 ladies than day 1 . They presumed that in ladies who are possibility for in vitro treatment or incipient organism move, it very well may be prescribed to start $\mathrm{CC}$ on day 5 of the cycle.

Despite the fact that $\mathrm{CC}$ is exceptionally effective in inciting ovulation, there is generally error among ovulation and pregnancy rates (just $40 \%$ of the individuals who ovulate will consider). This stamped inconsistency might be because of negative impacts of CC on oocytes or granulosa cells, or due to delayed antiestrogenic impacts of $\mathrm{CC}$ on endometrial receptivity and cervical bodily fluid, by hypersecretion of LH [18].

Roughly $15 \%$ of ladies who take CC have helpless post-coital test outcomes, and intrauterine insemination is suggested for these ladies [14].

Previously, estrogen was regulated from day 10 to day 16 of the period to improve bodily fluid creation, yet there are currently motivations to accept that estrogen organization is incapable [14].

A few investigations made it apparent that the previous the day of beginning $\mathrm{CC}$ the better the outcomes and that beginning $\mathrm{CC}$ on the very first moment or two of the cycle gives longer $\mathrm{CC}$ free periods before planned intercourse or IUI which brings about more fast follicular development, and higher ovulatory and pregnancy rates [10]. Anyway the origination rate couldn't be estimated in the current examination as it needs huge size of members with longer timeframe which was hard to accomplish it.

Albeit a few creators have hypothesized that CC directly affects the ovary [19, 20]. Some proof for inhibitory and stimulatory impacts of clomiphene on the ovary has been gotten in concentrates on refined follicles and luteal cells from people and test creatures.

Hammerstein et al., [19] found that clomiphene hinders progesterone creation by refined luteal cells of people and monkeys, despite the fact that the Westfahl and Resko, [20] saw in vivo concentrates on monkeys that it initiated an expansion in the serum level of progesterone without critical changes in the serum levels of LH and E2. The distinction in results acquired in vivo and in vitro might be clarified by the attributes of clomiphene and the reactions of tissues other than the corpus luteum just as by other obscure components [21].

Endometrial thickness is significant ultrasound boundary to evaluate endometrial receptivity which characterized as a timeframe during which the uterine climate is conductive to the blastocyst acknowledgment and implantation [22].

The consequence of this examination are in concurrence with the finding of Badawy et al., [10] who found that the endometrial thickness at the hour of hCG organization was essentially higher in the early CC (luteal acceptance) bunch contrasted with ladies in the late $\mathrm{CC}$ (follicular enlistment) gathering .

This might be clarified by the consequences of Takasaki et al., [23] who expressed that if CC treatment is begun from the get-go in the cycle, the negative impact of the medication on the endometrium (added to the moderately long half-existence of $\mathrm{CC}$ ) might be dodged.

Essentially, the aftereffects of the current investigation are in halfway concurrence with those of Farhi et al., [24] who detailed that the mean endometrial thickness at day of HCG organization was higher when $\mathrm{CC}$ was begun at day 5 of period than when $\mathrm{CC}$ was begun at day $\geq 7$ of feminine cycle.

Earthy colored and Farquhar, [25] detailed that helpless forecast for origination if the endometrial thickness on ultrasound filtering doesn't arrive at $8 \mathrm{~mm}$ at ovulation and whenever noted in the primary pattern of treatment with $\mathrm{CC}$, it will in all likelihood be seen in rehashed cycles in a similar lady. There is little point in enduring after even one cycle, and a stage up to different types of ovulation enlistment is suggested [26].

\section{Conclusion}

The consequence of the current examination recommended that early organization of $\mathrm{CC}$ in late luteal stage (before withdrawal shedding) in patients with PCOS may prompt more follicular development, ovulatory patients and endometrial thickness which may ponder higher pregnancy rate than organization of $\mathrm{CC}$ in early follicular stage (from second day to fifth day of cycle).

\section{References}

[1] H. Randeva, Is cardiovascular risk increased in women with polycystic ovarysyndrome? Endocrine Abstracts, Vol.49, PP.D4.1, 2017.

[2] M. J.Khan, A.Ullah, S Basit, Genetic Basis of Polycystic Ovary Syndrome (PCOS): Current Perspectives. The application of clinical genetics, Vol.12, PP. 249-260, 2019.

[3] S.El Hayek, L.Bitar, L.H.Hamdar, F.G.Mirza, Poly Cystic Ovarian Syndrome: An Updated Overview. Front Physiol, Vol.7,PP.124,2016.

[4] R.L.Rosenfield, The polycystic ovary morphologypolycystic ovary syndrome spectrum. J PediatrAdolescGynecol, Vol.28, PP.412-419, 2015.

[5] H.Escobar-Morreale, Polycystic ovary syndrome: definition, aetiology, diagnosis and treatment. Nat Rev Endocrinol, Vol.14, PP.270-284, 2018. 
[6] R.B.Mejia, K. M.Summers, J. D.Kresowik, B. J.VanVoorhis, A randomized controlled trial of combination letrozole and clomiphene citrate or letrozole alone for ovulation induction in women with polycystic ovary syndrome. Fertility and Sterility, 2019.

[7] R.S.Legro, R.G.Brzyski, M.P.Diamond, C.Coutifaris, Letrozole versus clomiphene for infertility in the polycystic ovary syndrome. New Eng J Med, Vol.371, PP.119-129, 2014.

[8] D. A.Dumesic, S. E.Oberfield, E. Stener-Victorin , J. C Marshall, Scientific Statement on the Diagnostic Criteria, Epidemiology, Pathophysiology, and Molecular Genetics of Polycystic Ovary Syndrome. Endocrine reviews, Vol.36(5), PP. 487-525, 2015.

[9] A. S.Melo, R. A.Ferriani, P. A. Navarro, Treatment of infertility in women with polycystic ovary syndrome: approach to clinical practice. Clinics (Sao Paulo, Brazil), Vol.70(11), PP.765-769, 2015.

[10] A.Badawy, H.Inany, A.Mosbah, M.Abulatta, Luteal phase clomiphene citrate for ovulation induction in women with polycystic ovary syndrome: a novel protocol. Fertility and Sterility, Vol.91(3), PP.838-41, 2009.

[11] O.Kosar, G.Ozaksit, M.I.Taskin,Luteal phase clomiphene citrate for ovulation induction in women with polycystic ovary syndrome. Archives of Gynecology and Obstetrics, Vol.290(4), PP.771-5, 2014.

[12] H.Gao, D. E.Liu, Y.Li, J.Tang, Uterine size and volume are associated with a higher clinical pregnancy rate in patients undergoing assisted reproduction technology: A longitudinal study (A STROBEcompliant article). Medicine, Vol.98(8), PP. e14366, 2019.

[13] R.Levesque, SPSS Programming and Data Management: A Guide for SPSS and SAS Users, SPSS Inc. Chicago Ill. PDF ISBN, Vol.1, PP.56827-390-8, 2007.

[14] L.Speroff, R.H. Glass, N.G. Kase, Induction of ovulation. Clinical gynecologic endocrinology and infertility J, Vol.81, PP.903-922, 2011.

[15] T. B.Mesen, S. L.Young, Progesterone and the luteal phase: a requisite to reproduction. Obstetrics and gynecology clinics of North America, Vol.42(1), PP. 135-151, 2015.

[16] Y. H.Chen, X. H.Xu, Q.Wang, S. D.Zhang, Optimum oocyte retrieved and transfer strategy in young women with normal ovarian reserve undergoing a long treatment protocol: a retrospective cohort study. Journal of assisted reproduction and genetics, Vol.32(10), PP. 1459-1467, 2015.

[17] M.Hembram, R.Biswas, A. A Jain, Study of Controlled Ovarian Stimulation with Clomiphene Citrate or Letrozole in Combination with Gonadotropins and IUI in Unexplained Infertility. Journal of human reproductive sciences, Vol.10(3), PP. 173-177, 2017.

[18] M.Y. Elsemary, W.F. G. Mostafa, O.S.ElTaher, Ovulation induction in women with polycystic ovarian syndrome: Clomiphene citrate or letrozole?. J Med Sci Res, Vol.1, PP.26-9, 2018.

[19] W.W.Hammerstein, E.M.Kolibianakis, H.Tournaye, P.Devroey,Inhibitory and stimulatory effect of CC on the ovary. FertilSteril, Vol. 87, PP. 9094, 2007.

[20] T.Westfahl, J.Resko,Difference in results between in vivo vs. in vitro response of ovary to CC. Best Pract Res ClinObstetGynaecol, Vol.18,PP.530-544,2008.

[21] J.F. Wilson,The Polycystic ovary Syndrome, Pathophysiology of PCOS, ClinEndocrinol (Oxf), Vol.154, PP.239-254, 2011

[22] M. S.Khan, A.Shaikh, R.Ratnani, Ultrasonography and Doppler Study to Predict Uterine Receptivity in Infertile Patients Undergoing Embryo Transfer. Journal of obstetrics and gynaecology of India, Vol.66(Suppl 1), PP.377-382, 2016.

[23] A.Takasaki, H.Tamura, T.Taketani, K.Shimamura, A pilot study to prevent a thin endometrium in patients undergoing clomiphene citrate treatment. Journal of ovarian research, Vol.6(1), PP. 94, 2013.

[24] J.Farhi, R.Orvieto, O. Gavisu, R.Homburg, The association between follicular size on human chorionic gonadotropin day and pregnancy rate in clomiphene citrate treated polycystic ovary syndrome patients. GynecolEndocrinol, Vol.26(7), PP.546-8, 2010.

[25] J.Brown, C.Farquhar, Clomiphene and other antioestrogens for ovulation induction in polycystic ovarian syndrome. The Cochrane database of systematic reviews, Vol.12, PP.(12), 2016.

[26] S.T.Dodge, R.C.Strickler, D.W.Keller,Ovulation induction with low doses of clomiphene citrate. ObstetGynecol, Vol. 67, PP.63S-65S, 2012. 